\title{
A Saturable, Vasopressin-Sensitive Carrier for Urea and Acetamide in the Toad Bladder Epithelial Cell
}

\author{
Sherman Levine, Nicholas Franki, and Richard M. Hays \\ From the Department of Medicine, Division of Nephrology, Albert Einstein \\ College of Medicine, Bronx, New York 10461
}

\begin{abstract}
A в S T R A C T The permeability of the toad bladder to a series of isotopically labeled nonelectrolytes was determined in the presence of $150 \mathrm{mM}$ unlabeled acetamide. Under these conditions, overall bladder function was unimpaired, as shown by a normal response to vasopressin of short-circuit current and permeability coefficient of $\left[{ }^{3} \mathrm{H}\right]$ water, $\left[{ }^{14} \mathrm{C}\right]$ ethanol, and $\left[{ }^{14} \mathrm{C}\right]$ propionamide. The permeability of the bladder to isotopic acetamide and urea, however, was significantly depressed by unlabeled acetamide, in both the absence and presence of vasopressin. These experiments indicate a competition between unlabeled and isotopic species for binding sites, and show the existence of a saturable, vasopressin-sensitive carrier for urea and acetamide in the epithelial cell membrane.
\end{abstract}

\section{INTRODUCTION}

There is evidence from studies in a number of species that urea movement across the renal tubule can proceed against a concentration gradient (1-4). While this suggests carrier-mediated transport, efforts to demonstrate a saturable urea carrier in the dogfish (5) and toad bladder (6) have been unsuccessful.

This work was presented in part at the 65th Annual Meeting of the American Society for Clinical Investigation, Atlantic City, New Jersey, April. 1973.

Dr. Levine is a Special Postdoctoral Fellow (1 FO 3 AM 53,207) of the National Institutes of Health; Dr. Hays is a Career Investigator, Health Research Council of the City of New York.

Received for publication 22 February 1973 and in revised form 4 June 1973.

The Journal of Clinical Investigation Volume 52 August 1973.2083-2086
We have recently shown that the movement of urea, other amides, thiourea, and formaldehyde across the toad bladder is sharply inhibited by phloretin in the luminal bathing medium, while the movement of water, sodium, ethanol, and ethylene glycol is unaffected (7). This finding has strengthened the case for carrier-mediated transport across the luminal cell membrane. We now wish to report studies showing that in the presence of high concentrations of unlabeled acetamide, the movement of isotopic urea and acetamide across the toad bladder is significantly depressed, providing direct evidence for a saturable, vasopressin-sensitive carrier for urea and acetamide.

\section{METHODS}

The permeability coefficients $\left(\mathrm{K}_{\mathrm{trans}}\right)^{1}$ of $\left[{ }^{14} \mathrm{C}\right]$ urea, acetamide, ethanol, and $\left[{ }^{3} \mathrm{H}\right]$ water were determined from lumen to serosa in paired bladder sacs tied to glass bungs and removed from Dominican toads (Bufo marinus, National Reagents, Bridgeport, Conn.). Control bladders were washed in a phosphate-buffered amphibian Ringer's solution (120 mM Na $, 4.0 \mathrm{mM} \mathrm{K}, 0.5 \mathrm{mM} \mathrm{Ca}^{++}, 116 \mathrm{mM} \mathrm{Cl}{ }^{-}$, $1.0 \mathrm{mM} \mathrm{H} \mathrm{PO}_{4}^{-}, 4.0 \mathrm{mM} \mathrm{HPO} 4^{--}, \mathrm{pH} \mathrm{7.4,} 230 \mathrm{mosm} / \mathrm{kg}$ $\mathrm{H}_{2} \mathrm{O}$ ), filled with $5 \mathrm{ml}$ of Ringer's solution containing the isotope to be studied, and placed in beakers containing 30 $\mathrm{ml}$ of Ringer's solution. Stirring was provided both inside and outside the sacs by rotating magnets (8). Paired test bladders were treated in the same fashion, except that the inside. and outside Ringer's solutions contained unlabeled acetamide, at identical inside and outside concentrations. In one set of experiments in which osmotic flow was determined, the osmotic gradient was created by decreasing the Ringer's solution to half strength inside both bags; $150 \mathrm{mM}$

${ }^{1}$ Abbreviation used in this paper: $\mathrm{K}_{\mathrm{trans}}$, permeability coefficient. 
TABLE I

Effect of Unlabeled Acetamide on $K_{\text {trans }}\left[{ }^{14} \mathrm{C}\right]$ Acetamide

\begin{tabular}{|c|c|c|c|c|c|c|}
\hline \multirow{2}{*}{$\begin{array}{l}\text { Unlabeled } \\
\text { Acetamide }\end{array}$} & \multicolumn{2}{|c|}{ Test bladder } & \multicolumn{2}{|c|}{ Control bladder } & \multicolumn{2}{|c|}{$\Delta$ (Control-test) $; P$ value } \\
\hline & $I^{*}$ & II & I & II & I & II \\
\hline$m M$ & & & & Lrane $\left(\mathrm{cm} \cdot \mathrm{s}^{-1}\right.$ & & \\
\hline $25(3) \ddagger$ & $33 \pm 6$ & $168 \pm 32$ & $33 \pm 1$ & $178 \pm 35$ & $0 \pm 7(\mathrm{NS})$ & $10 \pm 22(\mathrm{NS})$ \\
\hline $75(7)$ & $41 \pm 6$ & $149 \pm 16$ & $37 \pm 7$ & $148 \pm 10$ & $-4 \pm 2(\mathrm{NS})$ & $-1 \pm 15(\mathrm{NS})$ \\
\hline $125(8)$ & $50 \pm 11$ & $124 \pm 16$ & $50 \pm 10$ & $156 \pm 20$ & $0 \pm 3(\mathrm{NS})$ & $32 \pm 10(<0.02)$ \\
\hline $150(7)$ & $30 \pm 3$ & $110 \pm 12$ & $42 \pm 6$ & $165 \pm 24$ & $12 \pm 3(<0.01)$ & $55 \pm 16(<0.02)$ \\
\hline $150(6) \S$ & $13 \pm 1$ & $110 \pm 8$ & $17 \pm 1$ & $169 \pm 14$ & $4 \pm 1(<0.01)$ & $59 \pm 18(<0.02)$ \\
\hline
\end{tabular}

Standard errors of the mean are shown.

* Vasopressin added after period I. Period I, $15 \mathrm{~min}$; Period II, $30 \mathrm{~min}$ (mean of two 15-min periods).

$\ddagger$ Numbers in parentheses indicate number of experiments.

$\S$ Flux determined from serosa to lumen.

acetamide was present inside and outside the test bag. Short-circuit current was determined in Lucite chambers with a central dividing partition, with the same paired protocol as in the sac experiments. All isotopes were supplied by New England Nuclear, Boston, Mass. Counting was done in a Tri-Carb liquid scintillation counter (Packard Instrument Co., Downers Grove, Ill.). In all experiments, results obtained in the test bladder were compared to control bladders by the method of paired analysis (9). $K_{t r a n s}$ was determined for a single 15-min period before vasopressin, and for two consecutive 15-min periods after vasopressin. These two latter periods were combined into a single 30 -min period for ease of presentation.

\section{RESULTS}

The effect of increasing concentrations of unlabeled acetamide on $\mathrm{K}_{\text {trans }}\left[{ }^{14} \mathrm{C}\right]$ acetamide is shown in Table $\mathrm{I}$. There was no significant difference between test and control bladders at acetamide concentrations of 25 and

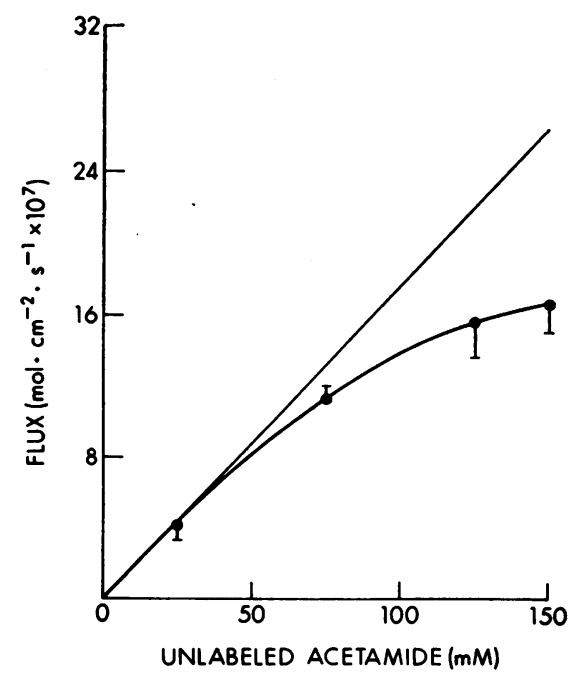

FIGURE 1 Velocity of unlabeled acetamide movement after vasopressin as a function of acetamide concentration.
$75 \mathrm{mM}$ in the test medium; at $125 \mathrm{mM}$, however, there was a significant depression of $\mathrm{K}_{\text {trans }}$ in the test bladder after vasopressin, and, at $150 \mathrm{mM}$, a depression both before and after vasopressin. The effect of $150 \mathrm{mM}$ acetamide on $\left[{ }^{14} \mathrm{C}\right]$ acetamide movement from serosa to lumen was identical to that from lumen to serosa (last line of Table I). Fig. 1 shows the data of Table I for the acetamide-treated bladder after vasopressin, plotted as the velocity of acetamide movement from lumen to serosa vs. unlabeled acetamide concentration. These values for velocity were calculated as $\mathrm{K}_{\text {trans }}\left[{ }^{14} \mathrm{C}\right]$ acetamide times concentration of unlabeled acetamide. A significant deviation of the test bladders from linearity is seen at acetamide concentrations of 125 and $150 \mathrm{mM}$.

The effect of $150 \mathrm{mM}$ unlabeled acetamide on the permeability of the bladder to a number of nonelectrolytes is shown in Table II. In addition to $\left[{ }^{14} \mathrm{C}\right]$ acetamide, unlabeled acetamide significantly depressed the movement of $\left[{ }^{14} \mathrm{C}\right]$ urea. In contrast, $\mathrm{K}_{\text {trans }}\left[{ }^{3} \mathrm{H}\right]$ water (determined simultaneously with $\left[{ }^{4} \mathrm{C}\right]$ acetamide), $\left[{ }^{14} \mathrm{C}\right]$ propionamide, and $\left[{ }^{14} \mathrm{C}\right]$ ethanol were unaffected by unlabeled acetamide. Osmotic water flow, determined gravimetrically in paired bags (see Methods), was also unaffected by $150 \mathrm{mM}$ acetamide (last line of Table II). The effect of $150 \mathrm{mM}$ acetamide on short-circuit current is shown in Fig. 2. In the absence of vasopressin, there was a small rise, then a fall, in short-circuit current in the acetamide-treated bladder half. The increment in shortcircuit current after vasopressin was identical in the control and acetamide-treated halves.

\section{DISCUSSION}

It has been known for some time that the effect of vasopressin on the movement of nonelectrolytes across the toad bladder is a selective one, and that factors other than molecular size or lipid solubility are involved in the hormone effect $(6,8)$. Coupled with this 
TABLE II

Effect of $150 \mathrm{mM}$ Acetamide on Bladder Permeability to Nonelectrolytes and on Osmotic Water Flow

\begin{tabular}{|c|c|c|c|c|c|c|}
\hline \multirow[b]{2}{*}{ Compound } & \multicolumn{2}{|c|}{ Test bladder } & \multicolumn{2}{|c|}{ Control bladder } & \multicolumn{2}{|c|}{$\Delta$ (Control-test); $P$ value } \\
\hline & I & II & $\mathbf{I}$ & II & I & II \\
\hline & \multicolumn{6}{|c|}{$K_{\text {trans }}\left(\mathrm{cm} \cdot \mathrm{s}^{-1} \times 10^{7}\right)$} \\
\hline$\left[{ }^{14} \mathrm{C}\right]$ Acetamide (7) & $30 \pm 3$ & $110 \pm 12$ & $42 \pm 6$ & $165 \pm 24$ & $12 \pm 3(<0.01)$ & $55 \pm 16(<0.02)$ \\
\hline$\left[{ }^{14} \mathrm{C}\right]$ Urea (10) & $46 \pm 13$ & $154 \pm 34$ & $72 \pm 18$ & $210 \pm 26$ & $26 \pm 8(<0.01)$ & $56 \pm 21(<0.05)$ \\
\hline$\left[{ }^{14} \mathrm{C}\right]$ Propionamide (4) & $62 \pm 13$ & $105 \pm 14$ & $57 \pm 4$ & $98 \pm 2$ & $-5 \pm 13(\mathrm{NS})$ & $-7 \pm 14(\mathrm{NS})$ \\
\hline$\left[{ }^{3} \mathrm{H}\right]$ Water (4) & $1187 \pm 97$ & $3102 \pm 55$ & $1155 \pm 117$ & $3150 \pm 166$ & $-33 \pm 42(\mathrm{NS})$ & $48 \pm 157(\mathrm{NS})$ \\
\hline$\left[{ }^{14} \mathrm{C}\right]$ Ethanol (4) & $1172 \pm 77$ & $1247 \pm 101$ & $1149 \pm 146$ & $1212 \pm 151$ & $-23 \pm 86(\mathrm{NS})$ & $-35 \pm 115(\mathrm{NS})$ \\
\hline \multicolumn{7}{|l|}{$\begin{array}{l}\text { Osmotic flow* (4), } \\
\mu l / s a c / m i n\end{array}$} \\
\hline$\mu l / s a c / \min$ & $1.5 \pm 0.3$ & $23.5 \pm 0.7$ & $1.2 \pm 0.2$ & $24.1 \pm 2.3$ & $-0.3 \pm 0.3(\mathrm{NS})$ & $0.7 \pm 1.7(\mathrm{NS})$ \\
\hline
\end{tabular}

Numbers in parentheses indicate number of experiments.

* Half-strength Ringer's in luminal solutions of test and control bladders; $150 \mathrm{nM}$ acetamide in luminal and serosal solutions of test bladders (see Methods).

observation is the evidence that in the dog (3), the protein-depleted sheep and rat $(1,2)$, and in the elasmobranch (4), renal urea reabsorption appears to proceed against a concentration gradient. Thus, the selectivity of solute movement and the apparent "uphill" transport of urea suggest that carrier-mediated movement may be involved. However, attempts to obtain direct evidence for a carrier by demonstrating saturation kinetics for urea transport were unsuccessful. Kempton was unable to show saturation for urea reabsorption by the dogfish kidney at plasma urea concentrations as high as $750 \mathrm{mM}$ (5) ; Leaf and Hays (6) concluded that competition between $0.1 \mathrm{M}$ unlabeled urea and isotopic urea, and between 0.1 to $0.6 \mathrm{M}$ acetamide and labeled dimethyl formamide or nicotinamide, could not be demonstrated in the toad bladder. ${ }^{2}$

The present experiments were carried out at concentrations of unlabeled acetamide from 25 to $150 \mathrm{mM}$ bathing both sides of the bladder. Under these conditions, permeability to $\left[{ }^{3} \mathrm{H}\right]$ water, $\left[{ }^{14} \mathrm{C}\right]$ propionamide, and ethanol was unchanged, in both the presence and absence of vasopressin, and the response of short-circuit current to vasopressin was maintained. Osmotic water flow after vasopressin was unimpaired. In addition, there was no significant difference in the ohmic resistance of the acetamide-treated and control bladders in the split chambers, after the addition of either acetamide or vasopressin. There was a small increase in outward water movement in the acetamide-treated sacs in the absence of an osmotic gradient when compared to their paired controls :

\footnotetext{
${ }^{2}$ It is of interest that a depression of $K_{\text {trans }}$ nicotinamide was apparent at the lower concentrations of unlabeled acetamide in these experiments, but was not consistently observed at $0.6 \mathrm{M}$ acetamide, a level which may have interfered with the integrity of the bladder. We noted in the present experiments that at $200 \mathrm{mM}$ acetamide, potential across the bladder was not consistently maintained.
}

at $125 \mathrm{mM}$ acetamide, net water flow was 1.8 compared to $1.3 \mu \mathrm{l} / \mathrm{sac} / \mathrm{min}$ in the control $(\Delta=0.5 \pm 0.1 \mu \mathrm{l} / \mathrm{sac} /$ $\min ; P<0.01)$; at $150 \mathrm{mM}$ acetamide, net water flow was 2.3 compared to $1.3 \mu \mathrm{l} / \mathrm{sac} / \mathrm{min}$ in the control $(\Delta=$ $1.0 \pm 0.2 ; P<0.001)$. The small increase in net water flow, however, was in the outward direction and would not have depressed $\mathrm{K}_{\mathrm{trans}}$ urea or acetamide. Thus, with respect to its permeability to sodium, water, and many nonelectrolytes, the bladder functioned normally in the

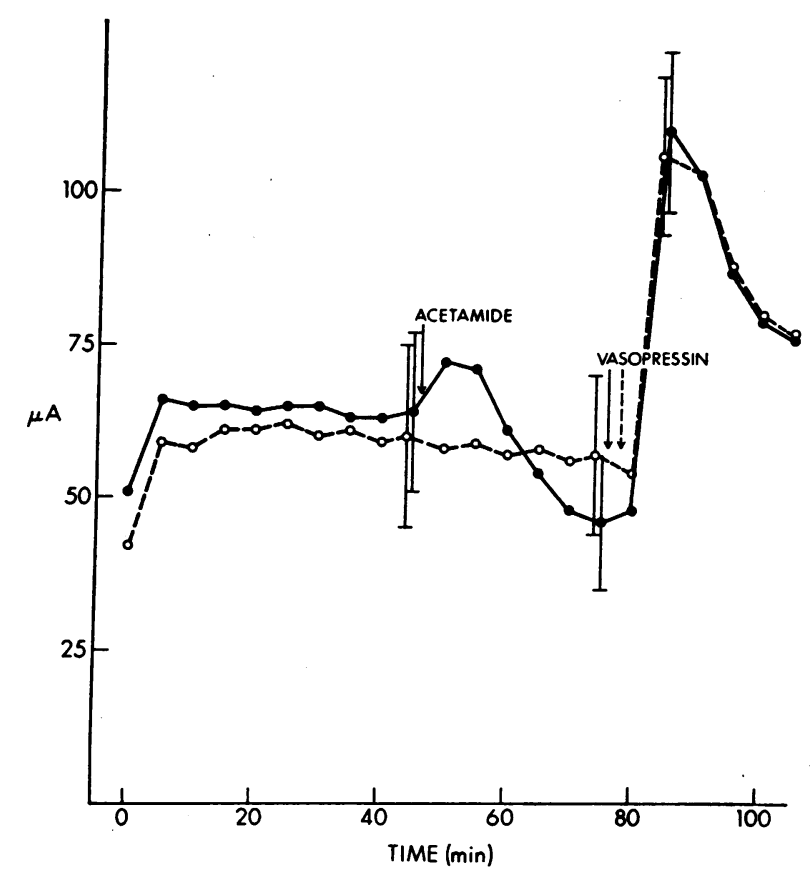

FIGURE 2 Short-circuit current in test bladders (closed circles) and control bladders (open circles), determined in divided chamber; four paired experiments. Vertical bars: \pm 1 SEM. 
presence of acetamide. In this setting, the depression of isotopic urea and acetamide transport by unlabeled acetamide would appear to be the result of a specific competition between the labeled and unlabeled species for carrier sites. Depression of isotopic acetamide movement was seen at 125 and $150 \mathrm{mM}$ unlabeled acetamide; a smaller depression was probably present at lower acetamide concentrations, but was undetectable by our present method. The absence of an acetamide effect on $\mathrm{K}_{\text {trans }}$ ethanol and water is consistent with our earlier observation that the permeability of these two molecules is not reduced by phloretin (7) and that they presumably move across the cell membrane via one or more different pathways.

The action of unlabeled acetamide does not appear to be the result of a nonspecific osmotic effect on the bladder epithelial cells. When $150 \mathrm{mM}$ raffinose, a large impermeable molecule with a reflection coefficient of 1.0 (8), was substituted for acetamide, short-circuit current fell promptly to zero, and did not respond to vasopressin, indicating a deterioration in over-all bladder function. At a lower concentration of $30 \mathrm{mM}$, raffinose did not depress short-circuit current, potential, or permeability to water, before or after vasopressin, and $\mathrm{K}_{\text {trans }}\left[{ }^{14} \mathrm{C}\right]$ acetamide was accelerated, rather than depressed, when compared to control bladders. Ethylene glycol, a small permeable molecule which is phloretininsensitive (7), had no adverse effect on short-circuit current or potential at $150 \mathrm{mM}$, and had no effect on $\mathrm{K}_{\text {trans }}\left[{ }^{14} \mathrm{C}\right]$ acetamide.

Of great interest is the failure of acetamide to displace $\left[{ }^{14} \mathrm{C}\right]$ propionamide from the carrier. Both compounds are amides, both are vasopressin-sensitive, and both are inhibited by phloretin (7). Propionamide has a more lipid-soluble side group than acetamide, and may be strongly bound to a lipid component of the carrier as well as to the "amide-binding" site; alternatively, propionamide may be bound to an adjoining carrier site, or may move via a different pathway altogether. This independent pathway would necessarily be a vasopressin- and phloretin-sensitive one. It is not yet possible to distinguish between these possibilities.

As far as the carrier itself is concerned, only a few of its general features are apparent at this point. The present studies do not distinguish between a mobile carrier and fixed binding sites for certain solutes. The carrier has a high capacity, and operates far from saturation over the narrow physiologic range of urea concentrations in toad urine (38 to $43 \mathrm{mM}$ [10]). This has the advantage for the toad of permitting urea reabsorption across the bladder to proceed at a maximal rate during the process of water reabsorption. If urea reabsorption were slowed by saturation of the carrier, its concentration in the bladder would rise more sharply, and decrease water reabsorption by approximately $20 \%$ (10). An analogous situation may be present in the dogfish renal tubule, where urea reabsorption apparently proceeds at a linear rate over plasma levels up to 750 $\mathrm{mM}$ (5). If a carrier is involved in this system, it may saturate at urea levels so high as to avoid any interference with reabsorption of the urea needed to maintain osmotic equilibrium in this species. While it is premature to describe urea movement across the renal tubule as carrier-mediated in all species, it is of some interest to ask whether differences in the urea permeability of various segments of the nephron reflect the number of carrier sites, and the urea levels at which they are saturated.

\section{ACKNOWLEDGMENTS}

This work was supported by Grants AM-03858, HL-05928, and HD-00674 from the U. S. Public Health Service, and 14-30-2900 from the Office of Saline Water, U. S. Department of the Interior.

\section{REFERENCES}

1. Schmidt-Nielsen, B., and R. O'Dell. 1959. Effect of diet on distribution of urea and electrolytes in kidneys of sheep. Am. J. Physiol. $197: 856$.

2. Clapp, J. R. 1966. Renal tubular reabsorption of urea in normal and protein-depleted rats. Am. J. Physiol. 210: 1304 .

3. Goldberg, M., A. M. Wojtczak, and M. A. Ramirez. 1967. Uphill transport of urea in the dog kidney: effects of certain inhibitors. J. Clin. Invest. 46: 388.

4. Schmidt-Nielsen, B., and L. Rabinowitz. 1964. Methylurea and acetamide: Active reabsorption by elasmobranch renal tubules. Science (Wash. D. C.). 146: 1587.

5. Kempton, R. T. 1953. Studies on the elasmobranch kidney. II. Reabsorption of urea by the smooth dogfish, Mustelus canis. Biol. Bull. (Woods Hole). 104: 45.

6. Leaf, A., and R. M. Hays. 1962. Permeability of the isolated toad bladder to solutes and its modification by vasopressin. J. Gen. Physiol. 45 : 921.

7. Levine, S., N. Franki, and R. M. Hays. 1973. The effect of phloretin on water and solute movement in the toad bladder. J. Clin. Invest. 52 : 1435.

8. Hays, R. M., S. H. Harkness, and N. Franki. 1970. The movement of urea and other small molecules across the toad bladder. In Urea and the Kidney. B. SchmidtNielsen, editor. Excerpta Medica Foundation, Publishers, Amsterdam. 149.

9. Snedecor, G. W., and W. G. Cochran. 1967. The comparison of two samples. In Statistical Methods. Iowa State University Press, Ames, Iowa. 6th edition. 91.

10. Maffly, R. H., R. M. Hays, E. Lamdin, and A. Leaf. 1960. The effect of neurohypophyseal hormones on the permeability of the toad bladder to urea. J. Clin. Invest. $39: 630$. 